\title{
Optimal start-up operating strategies for gas-boosted parabolic trough solar power plants
}

Ferruzza, Davide; Topel, Monika; Laumert, Björn; Haglind, Fredrik

Published in:

Solar Energy

Link to article, DOI:

10.1016/j.solener.2018.10.059

Publication date:

2018

Document Version

Peer reviewed version

Link back to DTU Orbit

Citation (APA):

Ferruzza, D., Topel, M., Laumert, B., \& Haglind, F. (2018). Optimal start-up operating strategies for gas-boosted parabolic trough solar power plants. Solar Energy, 176, 589-603. https://doi.org/10.1016/j.solener.2018.10.059

\section{General rights}

Copyright and moral rights for the publications made accessible in the public portal are retained by the authors and/or other copyright owners and it is a condition of accessing publications that users recognise and abide by the legal requirements associated with these rights.

- Users may download and print one copy of any publication from the public portal for the purpose of private study or research.

- You may not further distribute the material or use it for any profit-making activity or commercial gain

- You may freely distribute the URL identifying the publication in the public portal 


\section{Optimal start-up operating strategies for gas-boosted parabolic trough}

\section{2 solar power plants}

3 Davide Ferruzza ${ }^{1}$, Monika Topel ${ }^{2}$, Björn Laumert ${ }^{2}$, Fredrik Haglind ${ }^{1}$.

$4 \quad{ }^{1}$ Department of Mechanical Engineering, Technical University of Denmark, Nils Koppels Allé, Building 5 403, 2800 Kongens Lyngby, Denmark

$6 \quad{ }^{2}$ Department of Energy Technology, KTH Royal Institute of Technology, Sweden

7 *Phone number: +45 27296900, e-mail: daferr@mek.dtu.dk

8 Abstract

9 Concentrating solar power plants are taking an increasing share in the renewable energy generation market. Parabolic trough is one of such technologies and the most commercially mature. However, this technology still suffers from technical challenges that need to be addressed. As these power plants experience daily start-up procedures, the optimal performance in transient operation needs to be considered. This paper presents a performance based modelling tool for a gas-boosted parabolic trough power plant. The objective of the paper is to define an optimal operational strategy of the power plant start-up procedure with the aim of minimizing its fuel consumption while at the same time maximizing its electric energy output, taking into account all the thermo-mechanical constraints involved in the procedure. Heating rate constraints of the steam generator and the booster heater, and the steam turbine start-up schedule were considered. The simulation model was developed based on a power plant located near Abu Dhabi, and was validated against real operational data with a maximum integral relative deviation of $4.3 \%$ for gross electric energy production. A multi-objective optimization was performed for a typical operating week during winter and spring weather conditions. The results suggest that in order to minimize the fuel consumption and at the same time maximize the electric energy production, an evaporator heating rate of $6 \mathrm{~K} / \mathrm{min}$ is an optimal value both for winter and spring conditions. 
26 Nomenclature

27 ACC Air cooled condenser

28 BH Booster heater

29 CSPP Concentrating solar power plant

$30 \quad$ CT Cold tank

31 D Deaerator

32 DNI Direct normal irradiation

33 DSG Direct steam generator

34 ECO Economizer

35 EVA Evaporator

36 HT Hot tank

37 HTF Heat transfer fluid

38 HTFH Heat transfer fluid heater

39 HX Heat exchanger

40 LCOE Levelised cost of electricity

41 PB Power block

42 PSA Plataforma Solar de Almería

43 PT Parabolic trough 
44 PI Proportionate integrative

45 PTPP Parabolic trough power plant

46 RD Ramp delay

47 SAM System model advisor

48 SD Synchronization delay

$49 \quad$ SF $\quad$ Solar field

50 SGS Steam generator system

51 SH Super-heater

52 SM Solar multiple

53 Symbols

54 A Area $\left[\mathrm{m}^{2}\right]$

$55 \mathrm{~m} \quad$ Mass flow $\quad[\mathrm{kg} / \mathrm{s}]$

$56 \mathrm{p} \quad$ Pressure [bar]

57 Q Thermal energy [GWh]

$58 \mathrm{~T} \quad$ Temperature $\quad\left[{ }^{\circ} \mathrm{C}\right]$

$59 \mathrm{t} \quad$ Time $\quad[\mathrm{s}]$

$60 \mathrm{U} \quad$ Overall heat transfer coefficient $\left[\mathrm{W} /\left(\mathrm{m}^{2} \mathrm{~K}\right)\right]$

$61 \quad v_{\mathrm{T}} \quad$ Allowable ramp-up rate/heating rate $\quad[\mathrm{K} / \mathrm{min}]$

$62 \mathrm{~W} \quad$ Electric energy [GWh]

63 Subscripts 
max maximum

min minimum

\section{Introduction.}

The concentrating solar power (CSP) technology shows an increasing trend in capacity installations around the globe. One of the key reasons for this, is the possibility to integrate such technology with relatively cheap ways of storing thermal energy, hence allowing it to decouple the electric energy production from the solar input (International Energy Agency, 2014). Parabolic trough power plants (PTPPs) are the most mature and economically viable plants among the CSP technologies. They account for $85 \%$ of the current capacity installed (Groupe Reaction Inc., 2014; Khetarpal, 2016) and $80 \%$ considering the power plants currently planned to be installed (Estela et al., 2016). However, they still face problems both at technical and economic levels. From a technical stand-point, the intrinsic fluctuating nature of the solar irradiation causes operating challenges such as daily start-up procedures and frequent variations in loads, which some components of the plant are not fully designed to endure. From an economic perspective, CSP technologies are still not fully competitive with respect to traditional technologies such as gas or coal power plants. A way to improve the operating flexibility and the economic feasibility of PTPPs is to optimize the power block operation by maximizing its flexibility towards fluctuating loads and cyclic daily start-up procedures (Mancini et al., 2011). By doing so, it is possible to harvest as quickly as possible the solar irradiation, hence maximizing its electric energy production and profitability.

One of the key aspects to improve the technical performance of CSP plants is to increase the rate at which the plant can load-up in order to harness the solar energy quickly. On the other hand, in order to preserve the lifetime of certain components, the ramp-up rate is limited by thermo-mechanical constraints (Ferruzza et al., 2017). With regards to the power block this is especially true for the steam generator system (SGS) and the steam turbine (Ferruzza et al., 2017). For the former, the heating rate at which it can experience a temperature increase is limited by the thermo-mechanical stresses on the thick walled components and junctions such as the steam drum, super-heater headers and $\mathrm{T}$ or $\mathrm{Y}$ junctions in the steam 
pipelines (Dzierwa et al., 2016; Dzierwa and Taler, 2014; Taler et al., 2015b). Generally, the component limiting the ramp-up rate in the evaporator is the steam drum, which is designed as a high-pressure vessel, with a large diameter and consequently thick walls. The start-up procedure of the component is intended to reach as rapidly as possible nominal conditions for mass flow rates, pressure and temperature. In the case of the steam turbine, the shaft thickness is the main limiting aspect regarding thermal stresses. Therefore, in order to avoid excessive thermal stresses it is desirable to keep the temperature difference between the steam and the turbine metal as low as possible (Topel et al., 2015; Topel et al., 2017).

In order to achieve maximum responsiveness of the power plant towards a change in power load or insolation it is essential that all the components are able to start quickly thus enabling the CSP plants to start harvesting the incoming solar energy as soon as possible. However, there might be limiting factors for one component, which might reduce the required heating rate for another. For example, if the receiver or solar field are the limiting factors, there is no need for the SGS to be able to start up at a faster rate than that of the solar field. From a yearly perspective and optimization point of view, it might happen that a lower constraint is actually needed either for the steam turbine or the SGS. On the other hand, having for instance components like the SGS exceeding such optimal point might allow for more flexibility in the operational strategies of the power plant.

Considering previous work available in literature, research has been performed on modelling and evaluation of the performance of PTPPs with both oil and molten salts as heat transfer fluid, with and without gas-fired backup. For instance, Boukelia et al. $(2017,2015)$ investigated this by modelling specifically the power block in Ebsilon professional (STEAG, 2012) and evaluated the optimal levelised cost of electricity (LCOE) by means of artificial neural network algorithms implemented in Matlab. This, however, was done without considering detailed start-up constraints or different operating strategies. Biencinto et al. (2016) performed modelling of PTPPs both with nitrogen and Therminol-VP as heat transfer fluids. The model of the solar field was validated in detail against real plant data, while the overall model was compared with SAM (System advisor model) (Biencinto et al., 2014). In this case, the model was used to compare the annual yield of the two configurations. Bonilla and Jose (2012) modelled a direct solar steam generator PTPP using object-oriented modelling and calibrated it by comparing the model results with plant data from CIEMAT-PSA (Centro de Investigaciones Energéticas, Medioambientales y Tecnológicas - Plataforma Solar de Almería) by means of genetic algorithm based 
multi-objective optimization. The model focused mainly on the solar field detailed modelling and not on the overall power plant. Blanco et al. (2011) developed a model in the Wolfram mathematical software and compared the results to available power plant data. In this case, the power block was not modelled in detail, but used thermal efficiency correlations as function of the thermal input. Another example can be found in the work performed by Al-Hanaei et al. (2016), in which the authors developed a model of the Shams I power plant. The model did not consider the details of the power block and a validation was not presented in the paper. Detailed models can be also found in the research works presented by Sun et al. (2015) and Li et al.(2017b, 2017a, 2017c), in which the authors developed a multi-dimensional model to address optical, hydraulic and thermo-elastic issues during the operation of a direct steam generator (DSG) parabolic trough collector. Even though the authors addressed the thermo-elastic problems and monitoring, they did not integrate the findings in the definition of an optimal start-up strategy.

In general, it may be claimed that many simulation tools are available to perform CSP plants design and performance evaluations. System Model Advisor (SAM) from NREL (National Renewable Energy Laboratories, USA) (Blair et al., 2008; Gilman et al., 2008; Price, 2003), Greenius (Dersch et al., 2011) from DLR (Deutschen Zentrums für Luft- und Raumfahrt) and Solergy from Sandia National laboratories (Stoddard et al., 1987) are commonly known tools in the CSP community. However, papers including detailed comparisons of simulation results with operational data of existing power plants are scarce. Concerning the start-up limitations, studies have been performed at component level. As for steam turbines, Topel et al. $(2015,2017)$ studied the thermo-mechanical limitations on steam turbines due to thermal stresses and start-up procedures. Concerning the steam generator system, Gomez et al. (2017) analysed such constraints for the heat exchangers and employed dynamic models for the stress evaluation. At system performance level, Topel et al. (2015) and Spelling et al. (2012) considered the impact of increasing the turbine flexibility with regards to the power plant performance. In a previous study, the authors of this paper analysed the mutual interdependencies between the turbine and steam generator and the impact of their constraints on a parabolic trough power plant performance (Ferruzza et al., 2017). However, no previous study addressed the optimization of the start-up operational strategy of a parabolic trough solar power plant considering thermo-mechanical constraints related to the steam generator, heat exchangers and steam turbine. Specifically, there are no studies available in literature that aim at lowering the fuel consumption of such plants by optimizing the start-up operating strategy. 
In this paper, a hybridized PTPP with a gas-fired booster located near Abu Dhabi is considered. The plant is also integrated with an additional heat transfer fluid heaters. The objective of the paper is to define an optimal operational start-up strategy of the power plant start-up procedure with the aim of minimizing its fuel consumption while at the same time maximizing its electric energy output, taking into account all the thermo-mechanical constraints involved in the procedure. This was done by taking into consideration the evaporator and booster heater heating rate constraints to verify how a dynamic performance oriented design for such components could lead to a higher flexibility from an operational standpoint. The optimal range for these constraints in order to satisfy the aforementioned objective were determined. The numerical model was thoroughly validated considering the steady state and transient performances using two sets of operational data of a power plant located near Abu Dhabi.

In section 2 the paper presents the methods used to model the plant and validate it against operational data. It summarizes the constraints taken into account in the start-up strategy and dynamic operation and the implementation of the operation of the power plant in the control logic. Lastly, it presents the multiobjective optimization routine implemented. Section 3 presents the results of the validation, and afterwards the results and discussion of the multi-objective optimization performed for two different weather conditions. Section 4 outlines the conclusions and final remarks.

\section{Methods}

The modelling of the PTPP was carried out in DYESOPT, a tool able to perform power plant steady state nominal design, performance evaluation and techno-economic calculations. The tool has been previously developed and validated at KTH, Royal Institute of Technology, Stockholm (Guédez, 2016; Spelling, 2013). Figure 1 illustrates the logic flow of information and calculations within the tool, where the grey and black boxes represent the inputs and outputs of the model respectively. In order to perform the power plant design, meteorological data and an operating strategy are the required inputs together with price data if economic calculations are required. The results of the design serve for the time-dependent performance evaluation, which is carried in TRNSYS (University of Wisconsin Madison., 1975). Lastly, the results are post-processed in Matlab to obtain the required performance indicators. If these involve economic indicators, cost functions and economics of the plant location are taken into consideration. The whole procedure can be coupled with a multi-objective optimizer. 


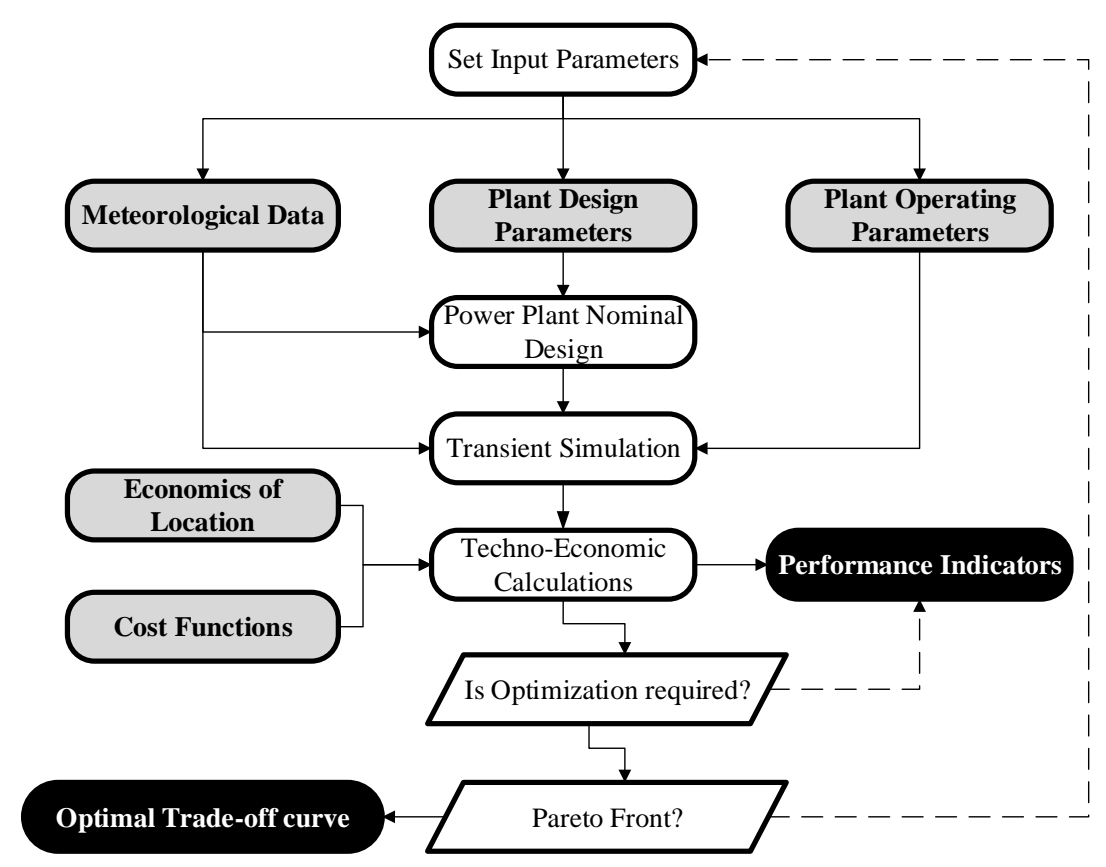

Figure 1: DYESOPT workflow diagram. Solid lines represent a YES logic while dashed lines represent a NO logic.

The steady state design and modelling of the power plant were developed and added to the tool. The sizing was performed in Matlab, while the dynamic modelling was performed in TRNSYS, and it was integrated with a control strategy to take into account the heating rate constraints during the start-up procedure. More details are provided in the following sections. DYESOPT incorporates a modified version of a queueing multi-objective optimizer (QMOO) based on a genetic algorithm developed at the Industrial Energy Systems Laboratory in Lausanne (Leyland and Favrat, 2002). Figure 1 shows the flow of information required for an optimization study. At the start of the optimization, it is possible to set conflicting objectives with regards to whether to maximize or minimize their quantities. Both design parameters and operation parameters can be set to allow for variation within the limits chosen for the study. The algorithm performs then as many iterations as needed to finalize the optimization and obtain an optimal trade-off curve or Pareto front.

\subsection{Heat exchangers heating rate constraints}

The details of the steam generator, heat transfer fluid heater and booster heater constraints are explained in the current section. As noted above, the rate at which each of them can start-up or heat-up is limited by 
material and geometrical constraints. As for the SGS start-up, previous studies (Basaran, 2015; Taler et al., 2015b) have shown that the main limiting components in this regard are the super-heater and the evaporator, hence these two were considered in detail in the current work. From a system perspective, the limit on the maximum allowable temperature difference for the heat exchangers is implemented in a control logic for the morning start-up procedures and daily transients. The minimum and maximum heating rates may be calculated based on the geometrical configuration and material specifications according to the norm DIN EN 12952-3 (CEN, 2012). However, the objective of this paper is to determine the optimal range of constraints from a system perspective, specifically tailored for start-up strategies. Such heating rates can be used to calculate the permitted fluid temperature change using the following equations (Taler et al., 2015b):

$$
\frac{d T_{\mathrm{f}}}{d t}=\frac{p_{\max } v_{\mathrm{T}_{\min }}-p_{\min } v_{\mathrm{T}_{\max }}}{p_{\max }-p_{\min }}+\frac{v_{T_{\max }}-v_{\mathrm{T}_{\min }}}{p_{\max }-p_{\min }} p\left(T_{\mathrm{f}}\right)
$$

These equations express the rate at which the fluid temperature $\left(T_{\mathrm{f}}\right)$ can change depending on the pressure of the fluid (minimum $\left(p_{\min }\right)$ and maximum $\left.\left(p_{\max }\right)\right)$ and the minimum and maximum heating rates $\left(v_{\mathrm{T}_{\min }}\right.$ and $\left.v_{\mathrm{T}_{\max }}\right)$ which are dependent on the geometry, material properties and operating temperature and pressure. In an evaporator, the water is at saturation point so the pressure and temperature are related. As a consequence, the temperature of the fluid will be dependent on the pressure, and Equation (1) can be solved using a Runge-Kutta method, assuming $T_{\mathrm{f}}(\mathrm{t}=0)=T_{0}$. In the case of the super-heater, the fluid is not at saturation conditions, the pressure is a function of time and determined by the evaporator conditions. The same considerations are applicable to both the HTF heater and the booster heater. In these cases as the two fluids considered (oil and super-heated steam) are not at saturation point.

\subsection{Steam turbine start-up schedule}

In order to capture a thorough start-up operation of the power plant, the TRNSYS model was implemented with a control strategy for the start-up of the steam turbine. The rate at which this component can increase its load is determined by the metal temperature at the beginning of the procedure. The warmer the turbine, the faster a start-up procedure will be. The turbine metal cool-down was modelled according to a lumped capacitance method (Bergman et al., 2011). Depending on the metal 
temperature, the appropriate start-up schedule curve was chosen in order to minimize the difference between the steam and metal temperatures. Once these are selected, the appropriate synchronization delay (SD) and the time for the turbine to reach full load (or ramp delay (RD)) are defined. Depending on the metal temperature, the start-ups can be generally classified as hot, warm and cold. A hot start-up typically takes only 8-10\% of the time it takes for a cold start-up, while a warm start-up requires between $45-50 \%$ of the time it takes for a cold start-up. Figure 2 illustrates the three main different start-up curves implemented in the transient model, with the A-B and B-C lines representing the synchronization delay and ramp delay, respectively for the cold case (Topel et al., 2015). Figure 3 illustrates the turbine start parameters such as pressure and temperature for a typical start-up schedule of the considered turbine.

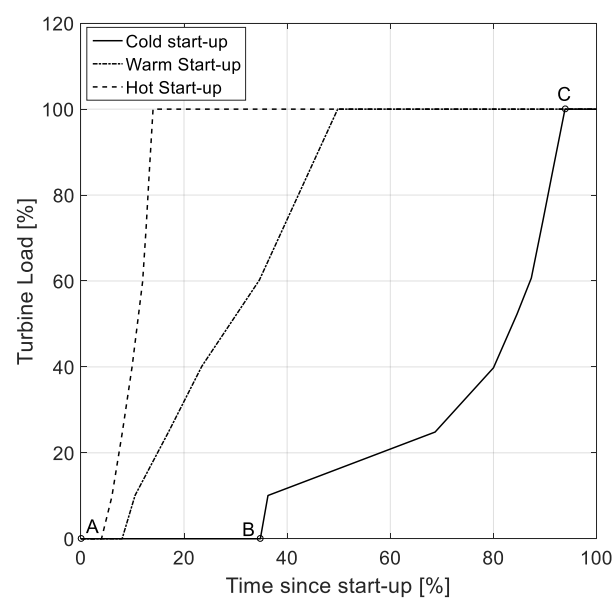

Figure 2: Cold, warm and hot steam turbine start-ups (adapted from Topel et al., (2015)).

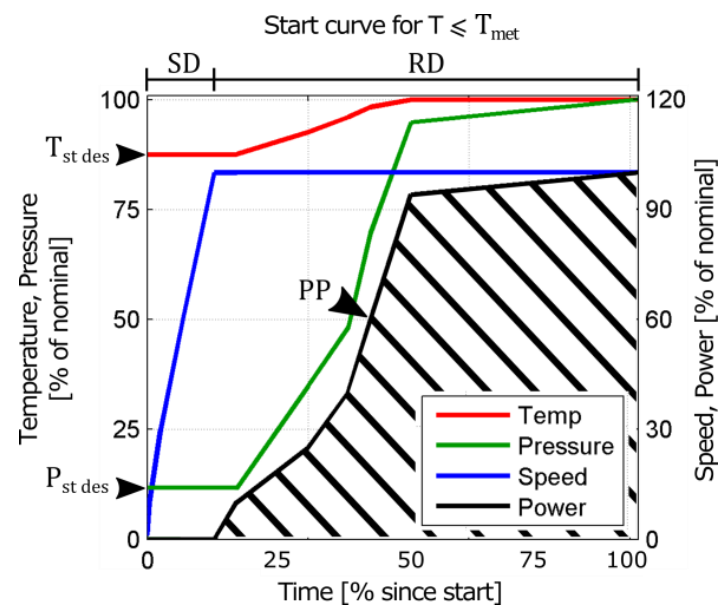

Figure 3: Turbine start parameters within a start-up schedule (Topel et al., 2015).

\subsection{Power plant modelling}

Figure 4 illustrates the power plant layout considered. The schematic layout of the plant is based on the configuration of a power plant located near Abu Dhabi (Alobaidli et al., 2017). The thick lines represent the heat transfer fluid loop. The oil is heated up by the parabolic trough (PT) collectors and pumped to the steam generator system, which comprises a super-heater (SH), an evaporator (EVA) and an economizer (ECO). In the morning when there is not high direct normal irradiation (DNI) a gas-fired heat transfer fluid heater $(\mathrm{HTFH})$ can be turned on to raise the temperature of the recirculating oil to the desired set point. The other cycle represents a conventional regenerative Rankine cycle with the only exception of the booster heater $(\mathrm{BH})$. The super-heater outlet steam temperature is raised to the turbine inlet 


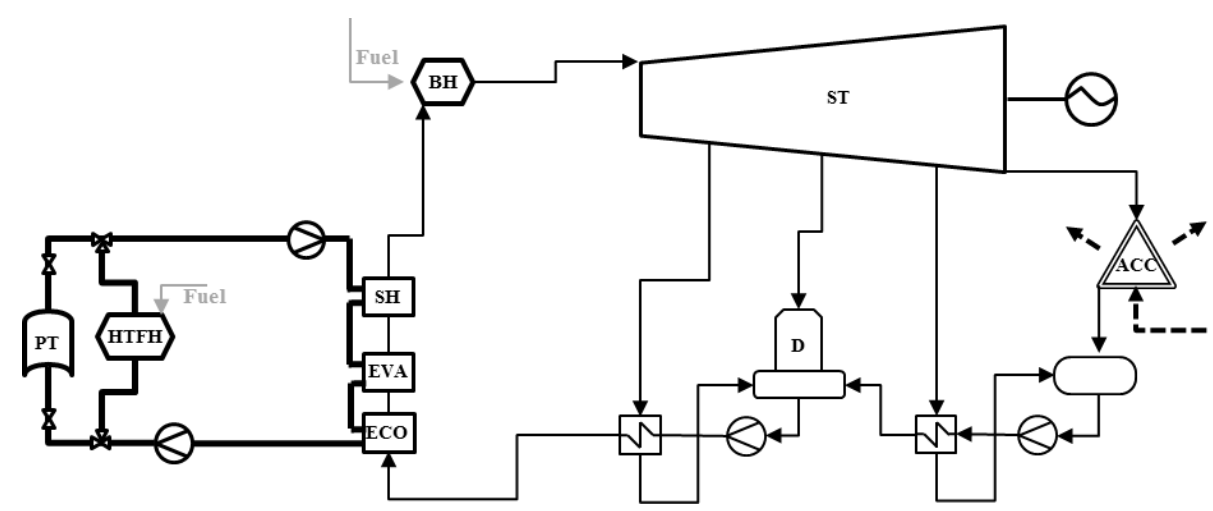

Figure 4: Layout of the considered parabolic trough power plant integrated with an oil heater and a booster heater (Alobaidli et al., 2017; Vogel et al., 2014).

Table 1: Design parameters of the power plant (Alobaidli et al., 2017; Vogel et al., 2014).

\begin{tabular}{lll}
\hline Start-up parameter & Units & Value \\
\hline Location & {$[-]$} & Abu Dhabi \\
Solar multiple & {$[-]$} & 1 \\
Gross power & {$[\mathrm{MWe}]$} & 124 \\
Power block nominal efficiency & {$[-]$} & 0.35 \\
Solar field aperture & {$\left[\mathrm{m}^{2}\right]$} & 627840 \\
Solar field nominal efficiency & {$[-]$} & 0.75 \\
Parabolic trough collector type & {$[-]$} & Astro \\
Solar field outlet temperature & {$\left[{ }^{\circ} \mathrm{C}\right]$} & 393 \\
Steam generator steam outlet temperature & {$\left[{ }^{\circ} \mathrm{C}\right]$} & 380 \\
Turbine inlet pressure & {$[\mathrm{bar}]$} & 100 \\
Condensation pressure & {$[\mathrm{bar}]$} & 0.17 \\
Turbine inlet temperature & {$\left[{ }^{\circ} \mathrm{C}\right]$} & 540 \\
Nominal condensing pressure & {$[\mathrm{bar}]$} & 0.13 \\
Operating strategy & {$[-]$} & Solar-driven \\
\hline
\end{tabular}

The equations of the zero-dimensional physical models governing the components are based on the STEC

library (DLR, 2006) for the power block. The inertia and response time of the components was taken into account by means of a lumped capacitance method (Bergman et al., 2011; DLR, 2006). The heat exchanger off-design models are based on scaling functions of the UA (overall heat transfer coefficient times area) value, which depends on the ratio of the actual cold side mass flow rate to that at the nominal point, while the turbine off-design performance was modelled according to the Stodola equations. The parabolic trough solar field was modelled taking into account optical efficiencies depending on the position of the sun, geometry of the collectors and weather conditions as well as thermal losses due to 
piping and expansion vessels (Dudley, 1994; Gilman et al., 2008; Lippke, 1995). The booster heater model is based on an efficiency map which depends on the steam inlet temperature according to the ASHRAE handbook (ASHRAE, 2000). Properties of the HTF were computed by linear interpolation in a data sheet from the oil manufacturer (Solutia, 2014).

The transient model of the plant was implemented with a logic controller to take into account the morning start-up strategies and hybridization with the HTF heater as well as the heating constraints for the abovementioned components. A summary of the morning start-up strategy is presented in Figure 5. Figure 6 presents a summary of the operating modes during the start-up. In the morning (as indicated by (1) in Figure 5) the main factors to account for, are the time at which the HTF heater is set to operate and when the PT can actually start to operate. These are choices usually set by the plant operator. In presence of DNI, the latter is allowed to operate after a certain time constraint, and more importantly, if the wind is below the maximum allowable threshold. Before that, the fluid is heated up by the HTFH (OM1). The start time of the HTFH is a variable which can be set in the plant operating parameters (see Figure 1). Once the HTF is heated up and reaches the minimum allowable temperature (as indicated by (2) in Figure 5) for the SGS, the HTF mass flow rate is calculated and the start-up procedure takes place (OM2). The oil temperature is raised according to the SGS heating-rate constraints. Lastly, the needed flow rate is pumped to the SGS. The same can happen if the DNI is high enough to start the solar field. In this case, the HTFH is turned off and the procedure is carried on in a solar only mode (OM3).

The steam coming from the SGS is heated up by the booster heater, which as well needs to comply with thermal stress constraints. In the meanwhile, the metal temperature of the steam turbine is checked, and if curve, which is dependent on the metal temperature. The steam temperature and pressure are raised according to the heating constraints and the mass flow rate is kept at a constant value during the rolling up phase (5\% of the nominal value (Schenk et al., 2015)) before the steam turbine can actually start to load up. The water mass flow rate raises and the nominal values can be reached (OM4) (as indicated by (3) in Figure 5). Once the procedure is terminated the plant enters into daily operation, taking into account both steady state performance and part-load performance when the DNI is not high enough according to DLR governing thermal stress constraints. 


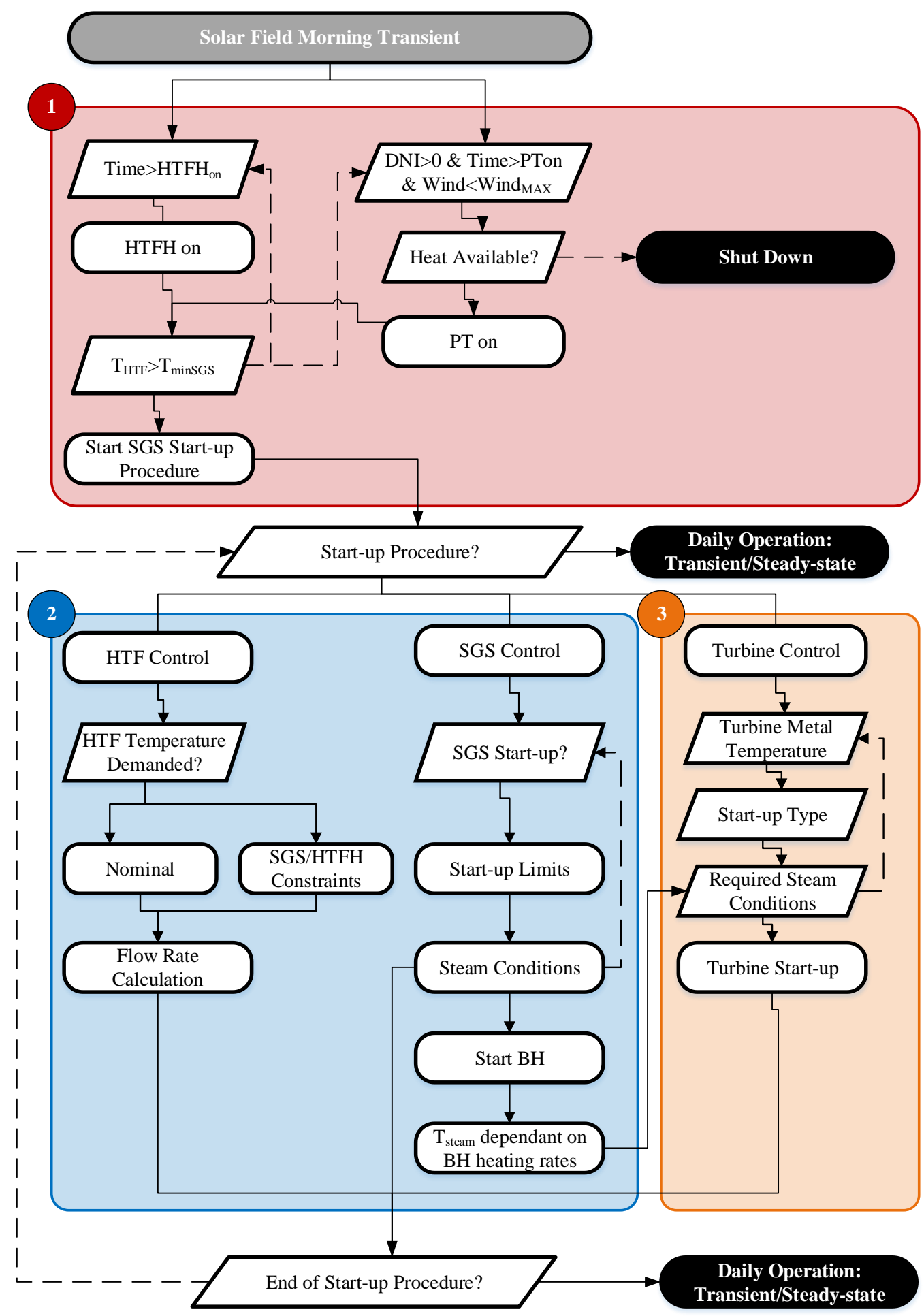

Figure 5: Morning start-up strategy control logic. Solid lines represent a YES logic while dashed lines represent a NO logic. Adapted from (Al-Hanaei et al., 2016; Ferruzza et al., 2018; Schenk et al., 2015). 


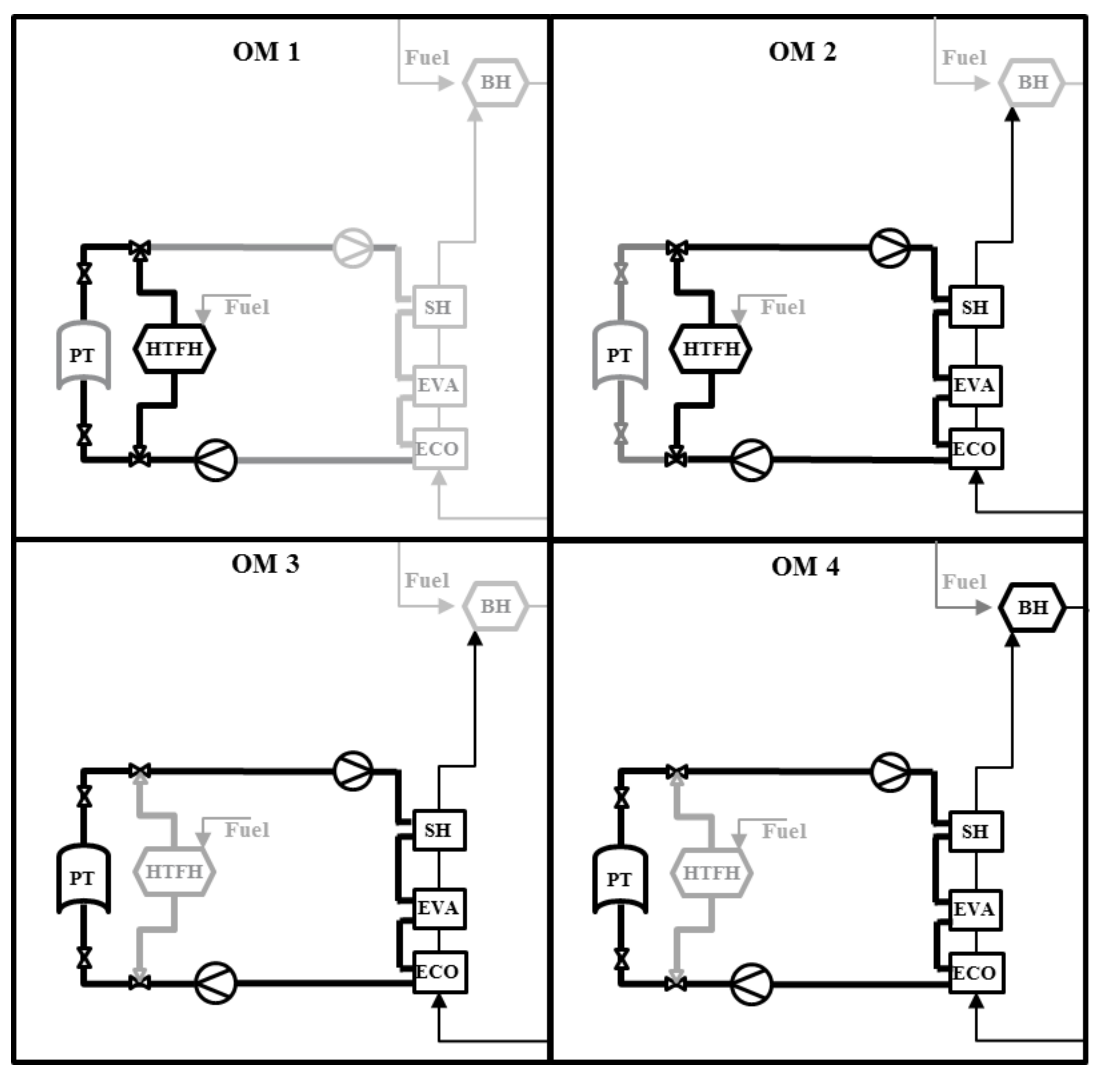

Figure 6: Operating modes $(\mathrm{OM})$ during the start-up of the steam generator.

\subsection{Multi-objective optimization}

The performance of the power plant can be measured by means of different indicators. For instance, when considering maximizing the electric energy generation of the considered power plant it is an intrinsic consequence to increase the fuel consumption. However, if the other objective is to minimize the fuel consumption, these two objectives will be in conflict. Hence, no single optimum solution exists but instead, for a given fuel consumption, a maximum electric energy production can be found, thus obtaining a trade-off of best operating designs considering fuel consumption and energy production. The optimization results can be used to choose an optimal start-up strategy for a particular requirement (Leyland and Favrat, 2002; Spelling, 2013). The objectives of the optimization were to minimize the fuel thermal energy consumption $\left(Q_{\text {fuel }}\right)$ and maximize the electric gross energy production $\left(W_{\text {gross }}\right)$. The decision variables chosen for the optimization studies are summarized in Table 2.

The optimization was performed for two seasons, winter and spring weather conditions, illustrating the operational flexibility of the plant throughout the year. The two periods chosen correspond to the data available for validation in order to show how the operation of the plant can be improved with the 
Table 2: Decision variables and constraints (Almasabi et al., 2015; Moya, 2012).

\begin{tabular}{llll}
\hline Parameter & Unit & Minimum value & Maximum Value \\
\hline EVA heating rate & {$[\mathrm{K} / \mathrm{min}]$} & 1 & 6 \\
BH heating rate & {$[\mathrm{K} / \mathrm{min}]$} & 1 & 6 \\
HTFH operating time & {$[\mathrm{h}]$} & 0 & 2.5 \\
HTFH T & {$\left[{ }^{\circ} \mathrm{C}\right]$} & 200 & 310 \\
\hline
\end{tabular}

proposed operating strategies. Using two different sets of weather conditions allows to see how the optimal operation strategy changes throughout the seasons considered. The minimum and maximum values of the decision variables were chosen to allow the possibility of radically different operating strategies. Having a higher pre-heating temperature would put less strain on the steam generator as it would need to cover a lower temperature difference to reach the nominal condition, which may result in lower optimal heating rates. Minimum and maximum heating rate constraint values were chosen as reference, and potential improvements were selected to reflect the best technologies commercially available. The ramp rate range of $3 \mathrm{~K} / \mathrm{min}$ to $9 \mathrm{~K} / \mathrm{min}$ represents a practically achievable range for commercially available steam generators (Aalborg CSP, 2015; Taler et al., 2015a). An intermediate value of $6 \mathrm{~K} / \mathrm{min}$ was chosen as the maximum value for the decision variables considered.
302 
314 rate and gross electric power. In order to quantify the reliability and accuracy of the model the following

315 indicators were used (Blanco et al., 2011):

$$
\begin{array}{cc}
\text { Integral relative error: } & I R E=\frac{\left(\int_{0}^{\text {time }}\left(y_{\text {model }}-y_{\text {data }}\right) d t\right)}{\left(\int_{0}^{\text {time }}\left(y_{\text {data }}\right) d t\right)} \\
\text { Root Mean Square Error: } & R M S E=\left(\frac{\sum\left(y_{\text {model }}-y_{\text {data }}\right)^{2}}{N}\right)^{\frac{1}{2}} \\
\text { Normalized RMSE: } & N R M S E=\frac{R M S E}{y_{\max }-y_{\min }}
\end{array}
$$

316 The Integral Relative Error (IRE) gives an overall measure throughout the simulation time considered of

317 the accuracy of the model. It quantifies the deviation of the integral result over the time period considered 318 between the model results and the available data. For example, if the gross power is considered, it will 319 give an estimation of the error of the electric energy produced throughout the time considered. The Root 320 Mean Square Error (RMSE) and normalized RMSE (NRMSE) give a measure of the instantaneous 321 accuracy of the model both in absolute and relative terms. The y values refer to the model and data sets 322 for a certain number of available data points $(\mathrm{N})$. 


\subsection{Validation of the model}

\begin{tabular}{llll}
\hline & Model & Data & Relative deviation \\
\hline Steam Generator Nominal thermal load & $207.3 \%$ & $207.5 \%$ & $-0.12 \%$ \\
Booster heater nominal thermal load & $45.6 \%$ & $47.0 \%$ & $-2.90 \%$ \\
Condenser nominal thermal load & $152.9 \%$ & $153.4 \%$ & $-0.36 \%$ \\
Power block net electric power output & $89.4 \%$ & $89.1 \%$ & $+0.39 \%$ \\
Parasitic consumption & $10.6 \%$ & $11.2 \%$ & $-5.13 \%$ \\
Solar + fuel to electricity efficiency & $28.34 \%$ & $28.57 \%$ & $-0.81 \%$ \\
\hline
\end{tabular}

Table 4: Results of the validation of mass flow rates (normalized values).

\begin{tabular}{llll}
\hline & Model & Data & Relative deviation \\
\hline SGS HTF mass flow rate & $869.66 \%$ & $931.67 \%$ & $-6.66 \%$ \\
SGS steam mass flow rate & $98.62 \%$ & $100.00 \%$ & $-1.38 \%$ \\
BH exhaust gas mass flow rate & $20.92 \%$ & $21.38 \%$ & $-2.13 \%$ \\
Condenser water mass flow rate & $72.71 \%$ & $72.67 \%$ & $+0.06 \%$ \\
\hline
\end{tabular}
attributed to the approximations made in the property calculations of the HTF (see Section 2.3). As the steam mass flow rate nominal value was used as normalization parameter for all the mass flow rate results, the HTF related results are higher than $100 \%$. This means that the required HTF mass flow rate is higher than the nominal turbine inlet mass flow rate. Lower deviations are found in the validation of the main parameters with a maximum error in absolute term of $-5.1 \%$ for the parasitic consumption. This deviation can be directly related to the lower nominal mass flow rate of the HTF which is required by the

340 SGS in the model and which would affect the parasitic consumption of the solar field. Based on the 341 results shown in the tables, it may be concluded that the plant sizing model provides reasonable results, which are sufficiently accurate in the context of the paper. 
The model was also validated for transient operation; Figure 7 illustrates the validation of the model for the data available between $16^{\text {th }}$ and $28^{\text {th }}$ of February, showing the common input for both the model and the operational data as summarized by Table 5. Temperature and pressure values were normalized with nominal turbine inlet temperature and pressure. The figure illustrates that the model is able to predict properly the trends of the main thermodynamic points and relative mass flow rates as well as produced electric power. The major deviations for each quantity, which may be observed in Figure 7, may be noticed at the end of the day (between 17.00-19.00), as (due to the high inertia of the parabolic trough solar field) the mass flow of the HTF is recirculated through the PT even though there is no DNI. This is done to exploit the remaining thermal inertia of the SF; however, the model is not able to fully capture this possibility. Another major deviation for each quantity may be observed on day 9 . In this case, the DNI is low but high enough to allow the operation of the solar field according to the constraints set in the model. However, the plant was not operated in that day, due to a decision of the operator. A similar consideration may be applied to the last day of the simulation.

Table 5 summarizes the relative error indicators as presented in section 2.5 and the RMSE values are normalized to the nominal reference values. The table illustrates that as an overall result (as integral over the days of the simulation) the model is accurate in predicting the performance of the power plant, with a maximum relative error of $3.9 \%$ for the flow rate of the HTF at the inlet of the SGS. Even though at nominal point the HTF mass flow is underestimated as noted in Table 4, the integral area is overestimated. This is mainly related to the days in which the power plant was not operated. The gross energy production validation resulted in $2.4 \%$ overestimation as compared to the operational data. Higher relative errors may be observed for the instantaneous validation. In this case the NRMSE goes up to +12 $\%$ for the HTF outlet temperature and $+8.6 \%$ for the gross electric power. Also in this case this can be related to a different operational decision of the operator. 
A) Direct normal irradiation $[\mathrm{W} / \mathrm{m} 2]$

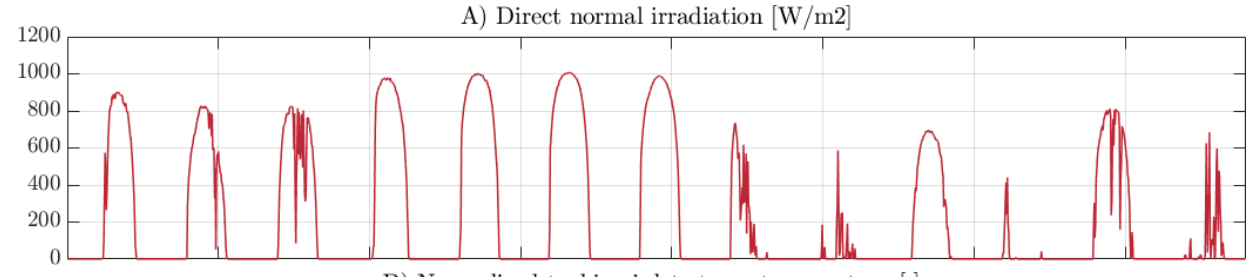

B) Normalized turbine inlet steam temperature [-]
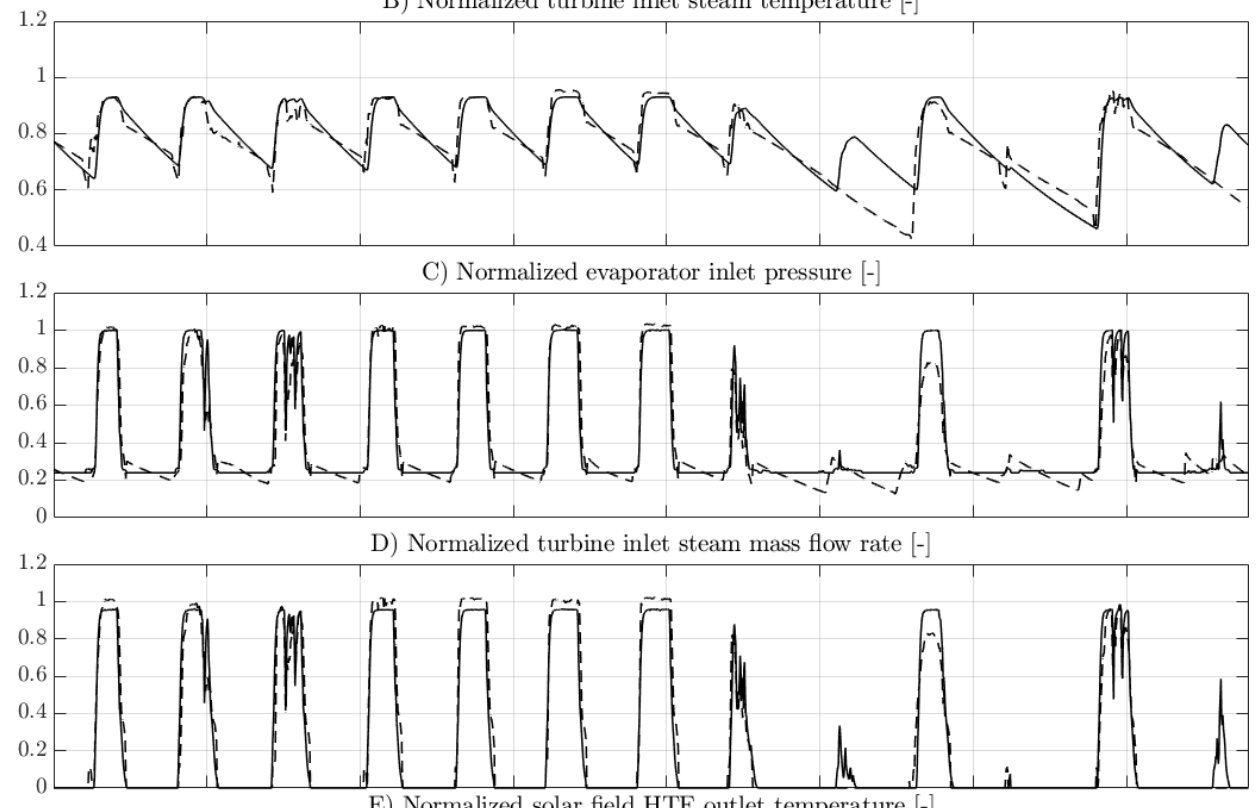

E) Normalized solar field HTF outlet temperature [-
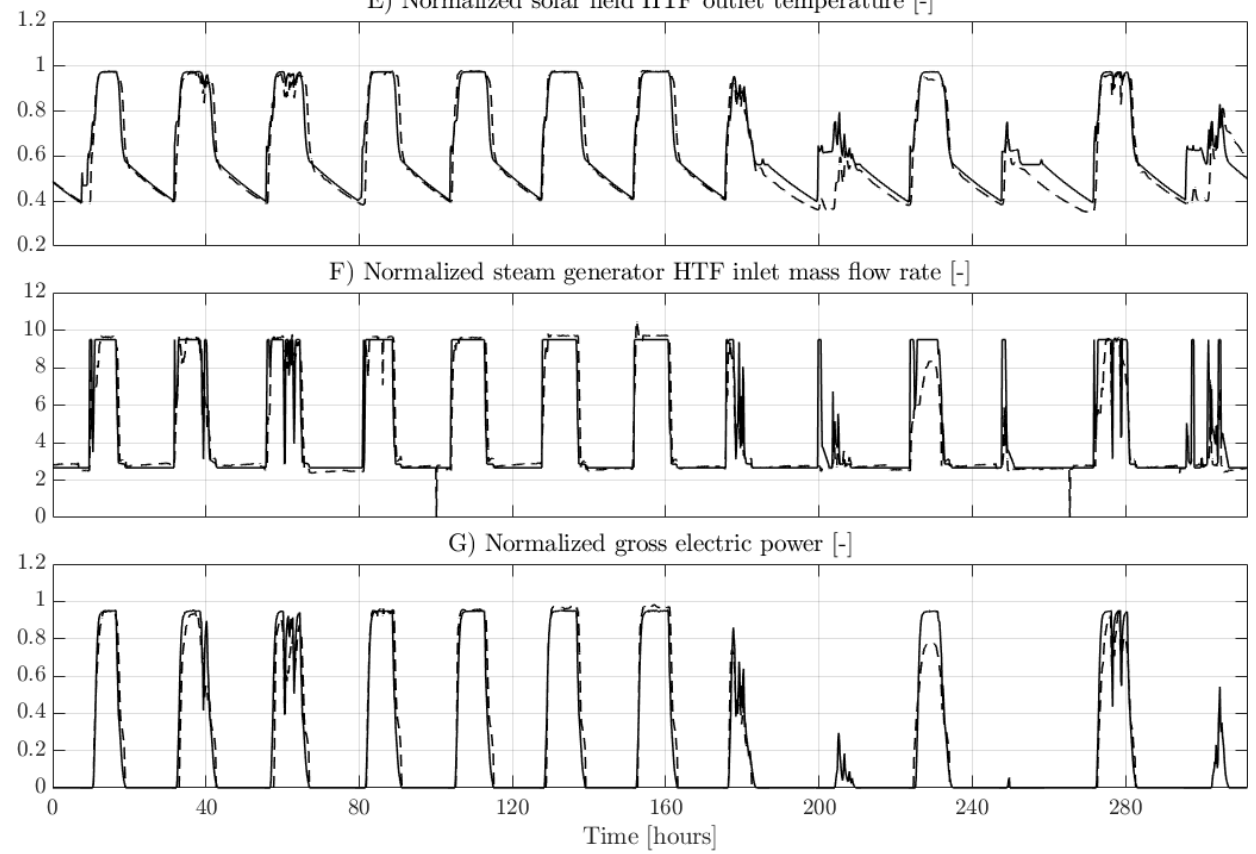

Figure 7: Validation for the winter case; A) DNI for the case considered (input), B) Normalized turbine inlet temperature, C) Normalized evaporator inlet water pressure, D) Normalized steam mass flow rate, E) Normalized solar field HTF outlet temperature, F) Normalized SGS HTF mass flow rate G)

Normalized gross electric power. The solid and dotted lines represent the result of the model and operational data, respectively. 
Table 5: Validation results for the winter case.

\begin{tabular}{llll}
\hline Parameter & IRE & RMSE & \\
TIT & {$[\%]$} & [\% of nominal reference values] & NRMSE [\%] \\
$p_{\text {in }}$ EVA & 2.25 & 7.35 & 9.66 \\
$F R_{\text {steam }}$ & 2.11 & 7.74 & 8.49 \\
$T_{H T F}$ & -2.57 & 8.56 & 8.34 \\
$F R_{\text {HTF }}$ & 3.19 & 7.62 & 12.00 \\
Gross power & 3.86 & 119.49 & 11.39 \\
\hline
\end{tabular}

Table 6: Validation results for the spring case.

\begin{tabular}{llll}
\hline Parameter & IRE & RMSE & NRMSE \\
{$[\%]$} & {$[\%$ of nominal reference values] } & 7.71 \\
\hline TIT & 2.97 & 6.41 & 9.12 \\
$p_{\text {in }}$ EVA & 1.02 & 7.98 & 9.72 \\
$F R_{\text {steam }}$ & -4.12 & 9.93 & 8.28 \\
$T_{\text {HTF }}$ & 1.67 & 5.63 & 13.54 \\
$F R_{H T F}$ & 4.76 & 139.17 & 10.32 \\
Gross Power & 4.32 & 10.23 & \\
\hline
\end{tabular}


A) Direct normal irradiation $[\mathrm{W} / \mathrm{m} 2]$

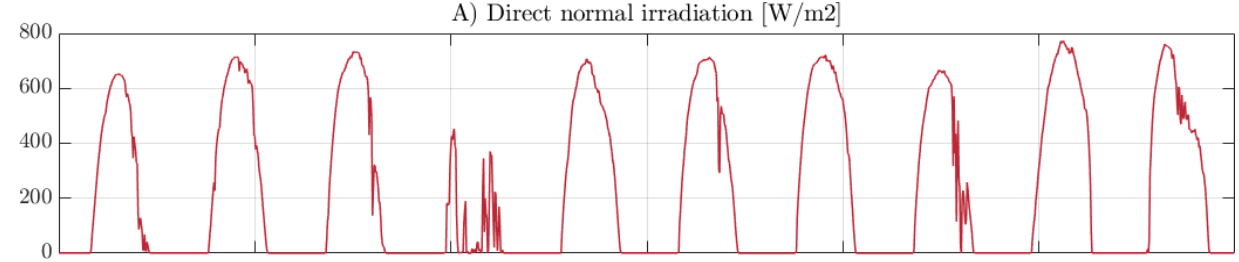

B) Normalized turbine inlet steam temperature [-]
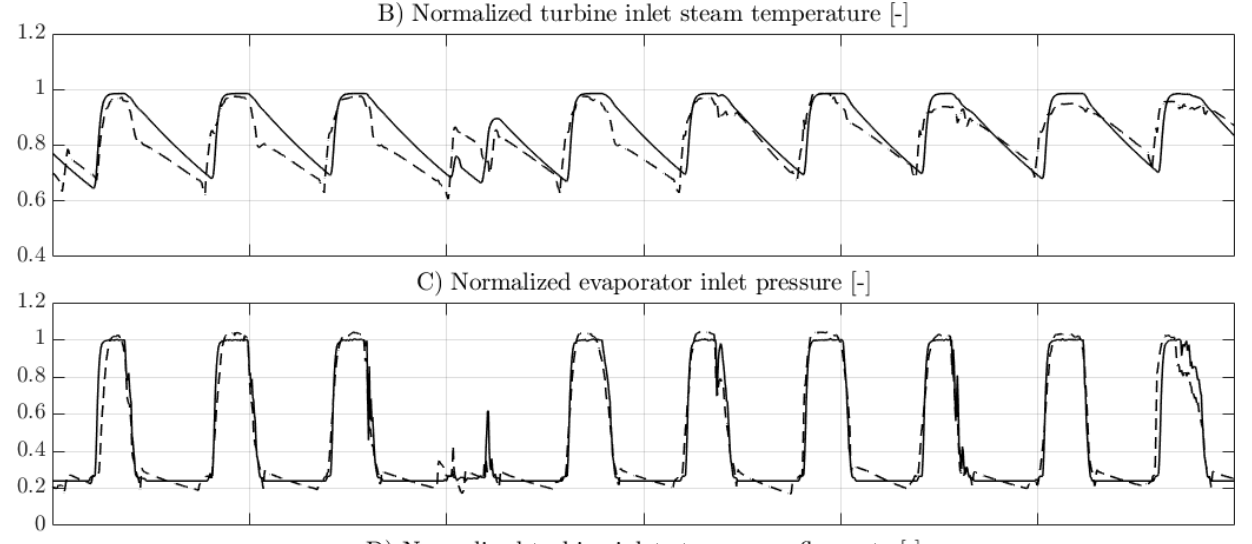

D) Normalized turbine inlet steam mass flow rate [-]

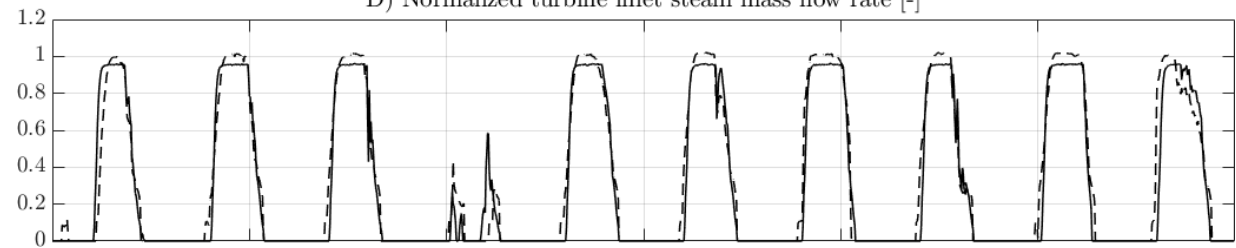

E) Normalized solar field HTF outlet temperature [-
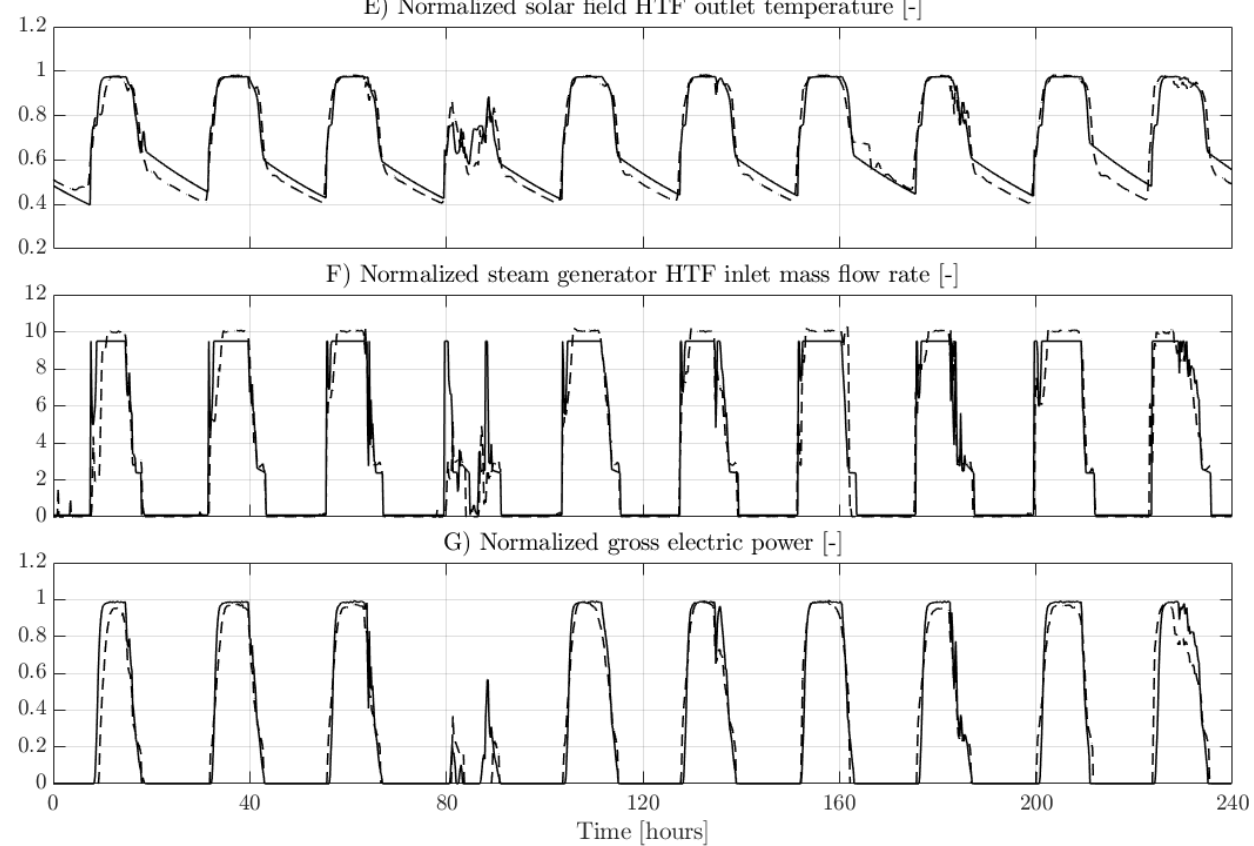

Figure 8: Validation for the spring case; A) DNI for the case considered (input), B) Normalized turbine inlet temperature, C) Normalized evaporator inlet water pressure, D) Normalized steam mass flow rate, E) Normalized solar field HTF outlet temperature, F) Normalized SGS HTF mass flow rate G)

Normalized gross electric power. The solid and dotted lines represent the result of the model and operational data, respectively. 
Moreover, a validation of the time delay until reaching experimental power output was carried out. Table

7 illustrates the results for such validation on a daily basis for both weather conditions. An average value of the absolute term of the deviations is also presented. It may be noticed that a significant deviation is observed for day $10 \mathrm{in}$ the winter case. This is mainly due to lower HTF mass flow rates caused by additional defocusing set by the plant operator, which is not reflected in the model. This is also why lower values are observable in Figure 7. Days 9, 11 and 13 were excluded from the winter related calculations as in those days the plant was not operated. The same reasoning applies for day 4 in the spring data set. Excluding these outliers, the highest deviation $(+11.1 \%)$ in rising time is observed for day 7 for winter conditions, which is illustrated in Figure 9 B. The lowest deviation is obtained in day $4(-0.46 \%)$ and the corresponding daily validation is depicted in Figure 9 A. Higher deviations (in absolute terms) are observed for the spring case with values up to $-15.6 \%$ in the case of day 8 (represented in Figure 9 D). A lower value, $-8.7 \%$, is observed for day 7 (represented in Figure $9 \mathrm{C}$ ). These deviations are mainly due to a more conservative approach employed by the operator in starting up the power plant during these periods. As an overall result, the absolute average deviation on the rise time is $7.9 \%$ and $11.8 \%$ for winter and spring weather conditions, respectively.

Table 7: Deviation results for rise time for gross power.

\begin{tabular}{ccc}
\hline & \multicolumn{2}{c}{ Deviation on rise time } \\
\hline Day & Winter & Spring \\
1 & $-6.8 \%$ & $-13.2 \%$ \\
2 & $-13.2 \%$ & $-11.9 \%$ \\
3 & $-10.2 \%$ & $-11.7 \%$ \\
4 & $-0.5 \%$ & - \\
5 & $5.3 \%$ & $-10.3 \%$ \\
6 & $5.0 \%$ & $-8.8 \%$ \\
7 & $11.1 \%$ & $-8.7 \%$ \\
8 & $10.0 \%$ & $-15.6 \%$ \\
9 & - & $-15.4 \%$ \\
10 & $-25.9 \%$ & $-10.5 \%$ \\
11 & - & \\
12 & $-9.1 \%$ & \\
13 & - & \\
Average (absolute value) & $7.9 \%$ & $11.8 \%$ \\
\hline
\end{tabular}



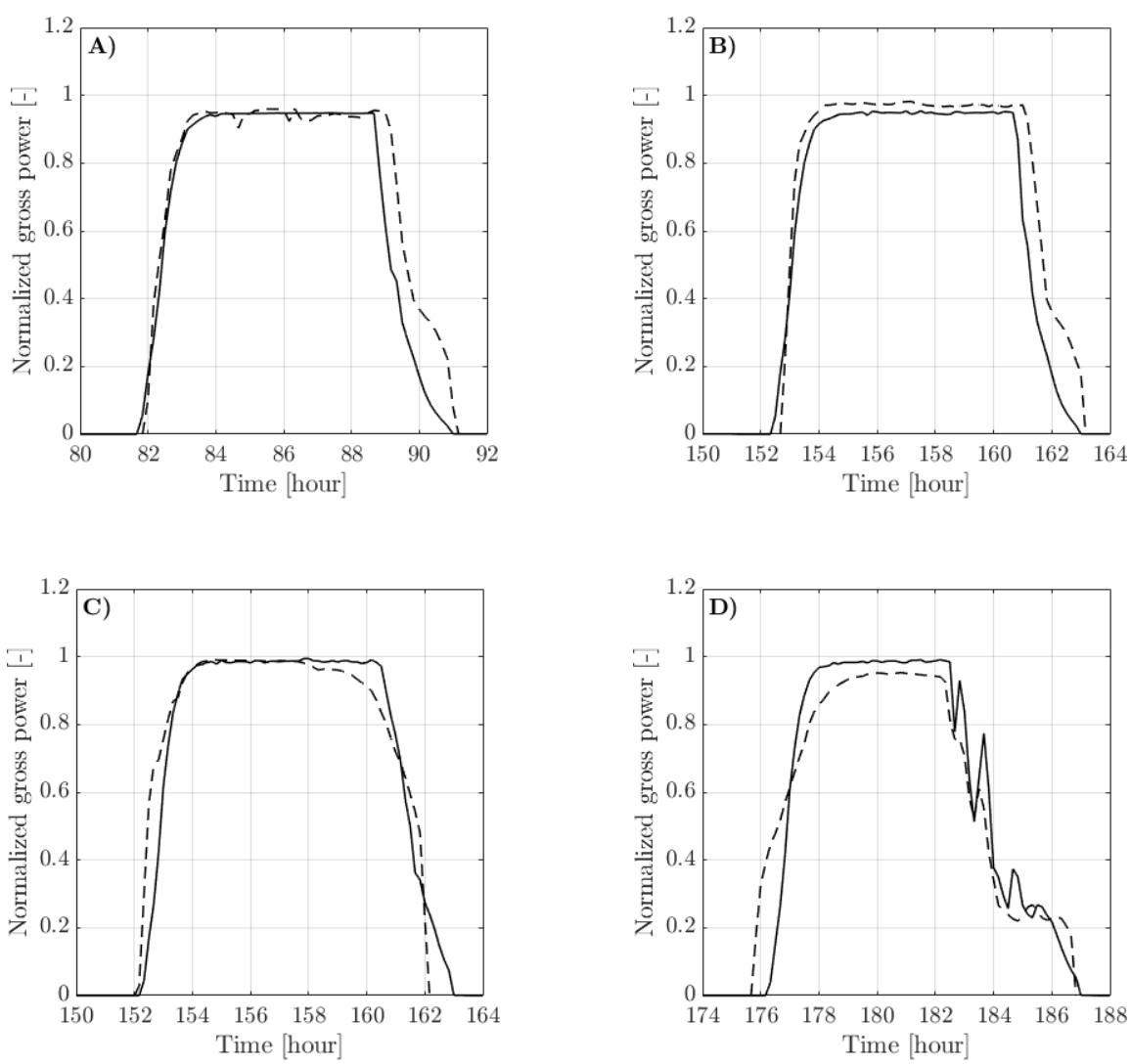

Figure 9: Close-ups on the transient daily validation results for the winter and spring data resulting in lowest $(\mathrm{A}, \mathrm{C})$ and highest deviations $(\mathrm{B}, \mathrm{D})$, respectively. The solid and dotted lines represent the result of the model and operational data, respectively.

The last step of the validation consists in comparing the estimated results of the model for the daily gross energy production with the equivalent operational data. Figure 10 illustrates such comparison in percentage form (the data were normalized against the maximum integral value obtained from the operational data sets). Figures $9 \mathrm{~A}$ and $9 \mathrm{~B}$ refer respectively to the winter and spring weather conditions. The dots represent the operational data points, while the dashed lines represent $\pm 10 \%$ and $\pm 5 \%$ deviation in the winter and spring case, respectively. For the spring case the results indicate that $80 \%$ of the values are within a $5 \%$ deviation while the two worst days are overestimated. In the winter weather conditions, the deviation slopes raise to $\pm 10 \%$ and in this case $85 \%$ of the points are within this margin. The other two points correspond to day 9 and 13 when the plant did not operate. In case of day 11 (on the $(0,0)$ coordinate in Figure 10 A) both the plant and the model predicts little to no electricity output and that is why even though the plant did not operate, no major discrepancies are observed. 

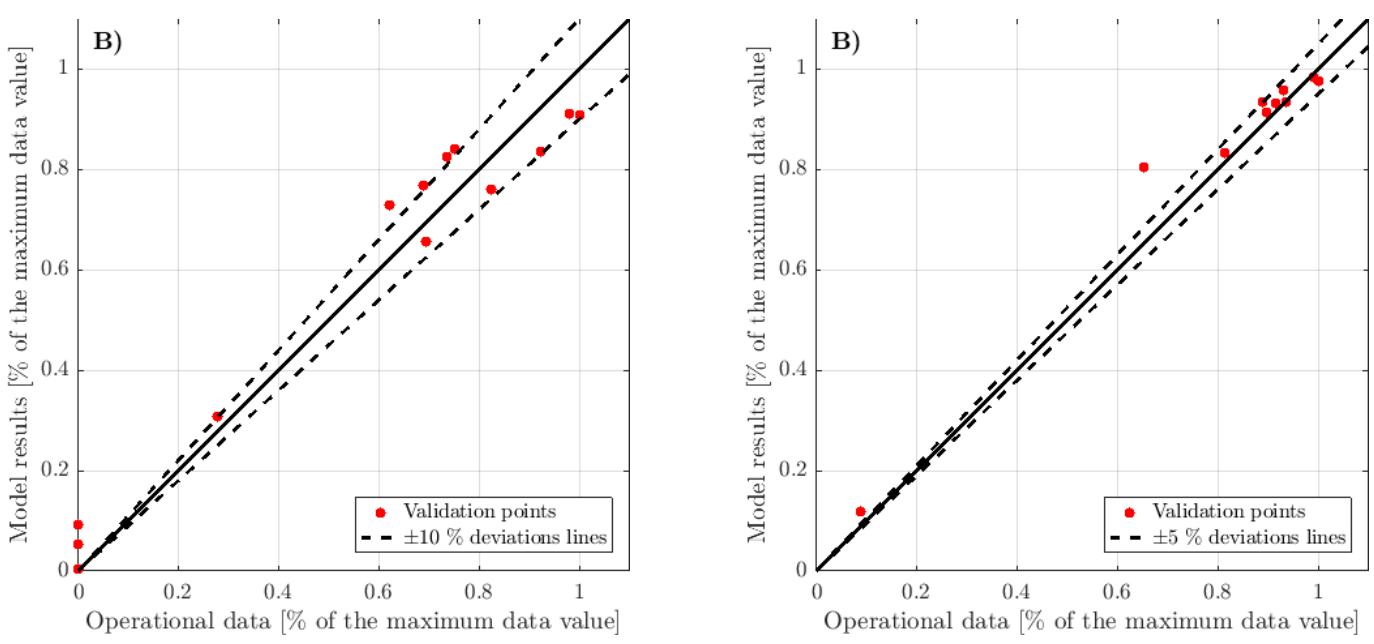

Figure 10: Comparison of the model results in terms of daily electric energy production for the days available in the data sets; A) February, B) May.

409 These observations support the aforementioned considerations on how the model differs more

410 significantly only when the plant decision makers decided to change the normal operating routines.

411 Overall, the results of Figure 10 suggest that the model is more accurate from an integral perspective in spring conditions as the deviations are essentially lower. On the other hand, the errors for the winter case compensate for each other making the IRE lower in this case. In conclusion, the results of the validation indicate that the model is able to predict the dynamic behavior of a gas-boosted parabolic trough solar power plant with reasonable accuracy, which is sufficient for the purpose of the study.

This section summarizes the results obtained for the optimization studies both for the winter and spring weather conditions. Figure 11 illustrates the results of the optimization for the winter case; the normalized objective variables (normalized with respect to the base case) are shown on the $x-y$-axes with one of the four decision variables (see Table 3) in each figure.

Figure 11 highlights four different points, respectively: 
iii. Trade-off between the two objectives in the form of minimizing the fuel to electricity ratio $\frac{\text { Qfuel }}{\text { Wgross }}$.

bc. Base Case (bc): Case used for the validation of the model.

Their operational parameters and results are summarized in Table 8. In general, the results shown in Figure 11 demonstrate that it is not possible to define a single optimal point for the start-up constraints both for the evaporator and the booster heater. However, it is possible to identify a range values maximizing the performance of the plant. For the evaporator, a range between 2.5 and $4.5 \mathrm{~K} / \mathrm{min}$ can be selected, including $47 \%$ of the points in Figure 11, and an optimal value of $5.7 \mathrm{~K} / \mathrm{min}$ is obtained in order to have a high electricity production without at the same time increasing significantly the fuel consumption. In case (iii), having a sufficiently high start-up constraint both for the evaporator and the super-heater allows for setting the temperature of the HTF heater to a low value of $200{ }^{\circ} \mathrm{C}$, minimizing significantly the fuel consumption. Case (ii) shows that in order to maximize the electricity production, not only it is necessary to have a higher set point for the HTF heater temperature (with the maximum operating time), but also it is required to have higher start-up constraints. This mainly relates to the operating choices, which would allow for more electric production by increasing significantly the fuel consumption. Table 8 and Figure 11 also indicate that the base case (bc) has a slightly higher fuel/electricity ratio than the optimal cases (i.e. cases close to point (iii)). By employing the start-up strategy depicted in case (iii) it is possible to lower the fuel/electricity ratio by $1.5 \%$ and increase the electricity production by $7.7 \%$, compared with the base case.

Table 8: winter case optimization results

\begin{tabular}{lllllll}
\hline EVA v & BH v & HTFH time & HTFH T & Normalized \\
Cases & {$[\mathrm{K} / \mathrm{min}]$} & {$[\mathrm{K} / \mathrm{min}]$} & {$[\mathrm{h}]$} & $\begin{array}{l}\text { Normalized } \\
{\left[{ }^{\circ} \mathrm{C}\right]}\end{array}$ & $\mathrm{W}_{\text {gross }}[-]$ & $\mathrm{Q}_{\text {fuel }}[-]$ \\
\hline bc & 1 & 4 & 2.5 & 310 & 1 & 1 \\
i & 1 & 1 & 1.58 & 238 & 0.836 & 0.845 \\
ii & 4.4 & 5.2 & 2.6 & 310 & 1.229 & 1.654 \\
iii & 5.7 & 5.6 & 2.4 & 200 & 1.077 & 1.067 \\
\hline
\end{tabular}



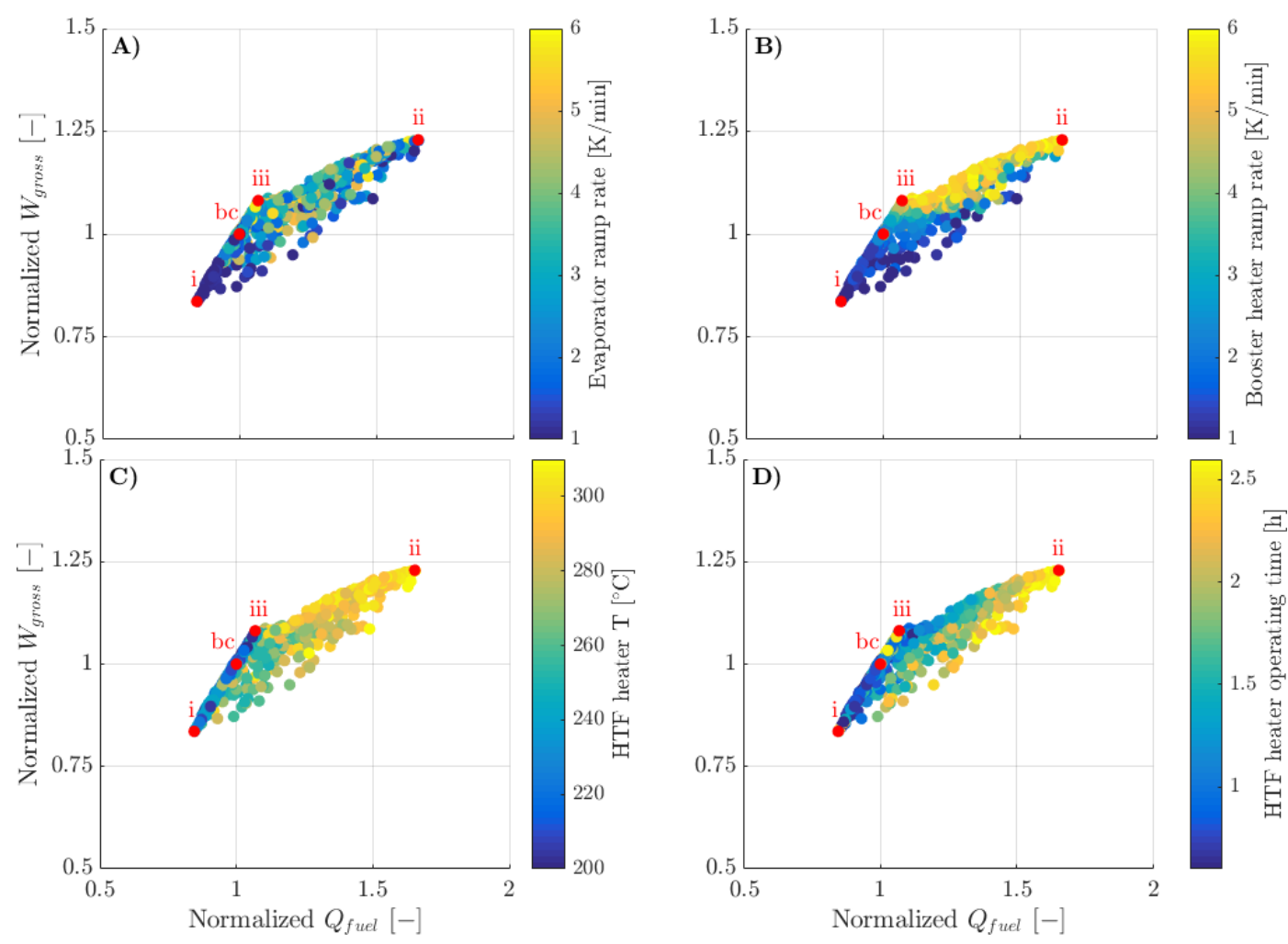

Figure 11: Optimization results for the winter case considering the different decision variables. Values normalized towards the base case results. A) Evaporator start-up rate constraints. B) Booster heater start-up rate. C) HTF heat Temperature D) HTF heater operating time.

These results indicate that it is not always necessary to have a SGS designed with high thermomechanical constraints. However, having such possibility can further increase the operational flexibility of the power plant. In this regard an analysis of the fuel efficient solution is performed. Figure 12 illustrates a close-up on case (iii), showing the fuel/electricity ratio as a function of the evaporator heating rate constraint. On the $\mathrm{z}$-axis color bar the booster heater heating rate constraints is shown. Table 9 summarizes the decision variables and objective functions of case (iii) and case (iv) and (v). 


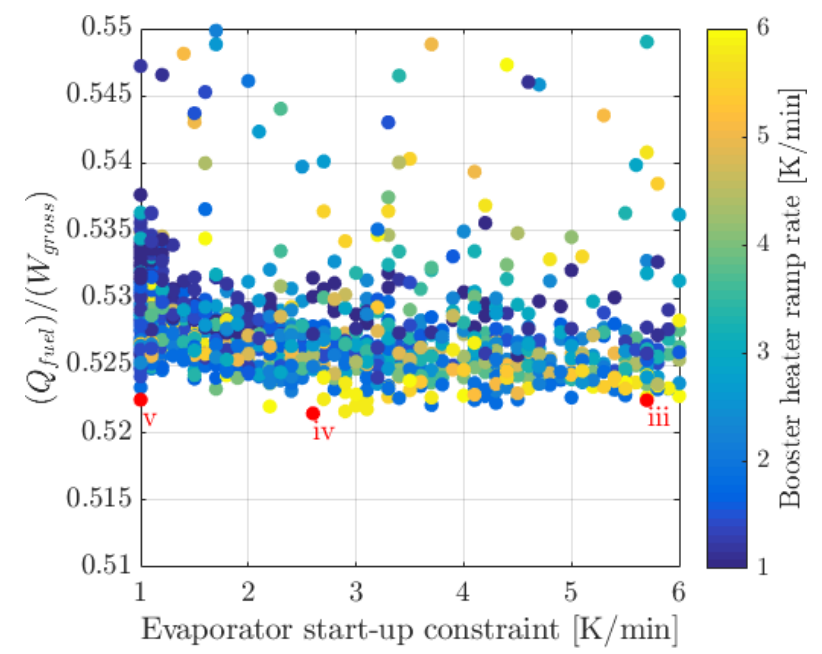

Figure 12: Analysis of evaporator constraints on the Fuel/Electricity ratio - Close-up on the optimal ratio $Q_{\text {fuel }} / \mathrm{W}_{\text {gross. }}$

Table 9: Optimal efficiency points comparison

\begin{tabular}{|c|c|c|c|c|c|c|}
\hline Cases & $\begin{array}{l}\text { EVA v } \\
{[\mathrm{K} / \mathrm{min}]}\end{array}$ & $\begin{array}{l}\mathrm{BH} \mathrm{v} \\
{[\mathrm{K} / \mathrm{min}]}\end{array}$ & $\begin{array}{l}\text { HTFH time } \\
{[\mathrm{h}]}\end{array}$ & $\begin{array}{l}\text { HTFH T } \\
{\left[{ }^{\circ} \mathrm{C}\right]}\end{array}$ & $\begin{array}{l}\text { Normalized } \\
\mathrm{W}_{\text {gross }}[-]\end{array}$ & $\begin{array}{l}\text { Normalized } \\
\text { Q fuel }[-]\end{array}$ \\
\hline iii & 5.7 & 5.6 & 2.43 & 200 & 1.077 & 1.067 \\
\hline iv & 2.6 & 6.0 & 2.12 & 220 & 1.082 & 1.069 \\
\hline $\mathrm{V}$ & 1 & 1.8 & 0.9 & 242 & 0.932 & 0.921 \\
\hline
\end{tabular}

451 These cases give very similar results, but employ different operating strategies. The results shown in

452 Table 9 and Figure 12 suggest that it is possible to obtain a slightly higher $(0.45 \%)$ gross electricity

453 production at the cost of increasing (by $0.22 \%$ ) the fuel consumption. However in this case, even though

454 lower constraints on the evaporator might be obtained, it would be required to increase the set-point

455 temperature of the HTFH and increasing the constraint of the booster heater. It is then preferable to

456 choose option (iii), as the heater would only be used to pre-heat the oil to a maximum temperature of 200

$457{ }^{\circ} \mathrm{C}$. In case it is not possible to employ a steam generator, which allows for such constraints as its design

458 might not allow for it, it is still possible to operate of the power plant in the optimal region at the cost of

459 employing the HTF heater for more time and at a higher temperature. In terms of fuel to electricity ratio, a

460 similar result can be obtained, see case (v), which represents a limit case for a very slow evaporator in

461 terms of heating rates. However, if the heating rates of the evaporator are constrained to the lower limit,

462 in order to have a similar fuel to electricity ratio (0.522) a much lower (-13.5\%) electric energy

463 production is achieved. 
The results of the multi-objective optimization for the spring season are summarized in Figure 13; the aforementioned four cases are also indicated in the figure. The base case is again below the Pareto front, meaning a non-optimal operating point. The detailed results of the different cases are presented in Table 10.

Table 10: spring case optimization results

\begin{tabular}{lllllll}
\hline Cases & $\begin{array}{l}\text { EVA v } \\
{[\mathrm{K} / \mathrm{min}]}\end{array}$ & $\begin{array}{l}\mathrm{BH} \mathrm{v} \\
{[\mathrm{K} / \mathrm{min}]}\end{array}$ & $\begin{array}{l}\text { HTFH time } \\
{[\mathrm{h}]}\end{array}$ & $\begin{array}{l}\text { HTFH T } \\
{\left[{ }^{\circ} \mathrm{C}\right]}\end{array}$ & $\begin{array}{l}\text { Normalized } \\
\mathrm{W}_{\text {gross }}[-]\end{array}$ & $\begin{array}{l}\text { Normalized } \\
\mathrm{Q}_{\text {fuel }}[-]\end{array}$ \\
\hline $\mathrm{bc}$ & 1.00 & 1.00 & 2.5 & 310.00 & 1 & 1 \\
$\mathrm{i}$ & 1 & 1 & 0.62 & 263 & 0.947 & 0.930 \\
ii & 4.3 & 4.3 & 1.83 & 281 & 1.134 & 1.211 \\
iii & 6 & 6 & 0.78 & 290 & 1.062 & 1.057 \\
\hline
\end{tabular}

In the spring case, higher optimal values (towards the upper boundary of the constraints) are obtained for the evaporator heating rates, especially for case (iii). As the heater is operated at a lower temperature, it is necessary to increase the start-up speed of the steam generator. Compared to the base case (bc), in case (iii), by increasing the fuel consumption $(+5.6 \%)$ it is possible to increase the electricity production by $6.2 \%$, decreasing the fuel to energy ratio. The results indicate that if the fuel consumption is set as a constraint, a higher electricity production $(+1.9 \%)$ can be achieved by increasing the heating rates to the maximum limits and at the same time decreasing the HTF heater utilization.

One of the main differences between Figure 11 and Figure 13 is the narrower range of solutions for the spring case. This can be directly linked to the lower fluctuations in the DNI and therefore a lower impact of the constraints on the electricity production, explaining why a lower value of the maximum heating rate constraint is obtained for case (ii). This would mean that having components designed for higher heating rates would enable a larger degree of flexibility in operating the power plant. In conclusion, the results suggest that there are no clear range of optimal values for the heating rates of the evaporator and booster heater. However, by being able to operate them at a faster rate it is possible to reduce the operating time of the HTF heater and maximize the electricity to fuel ratio. 

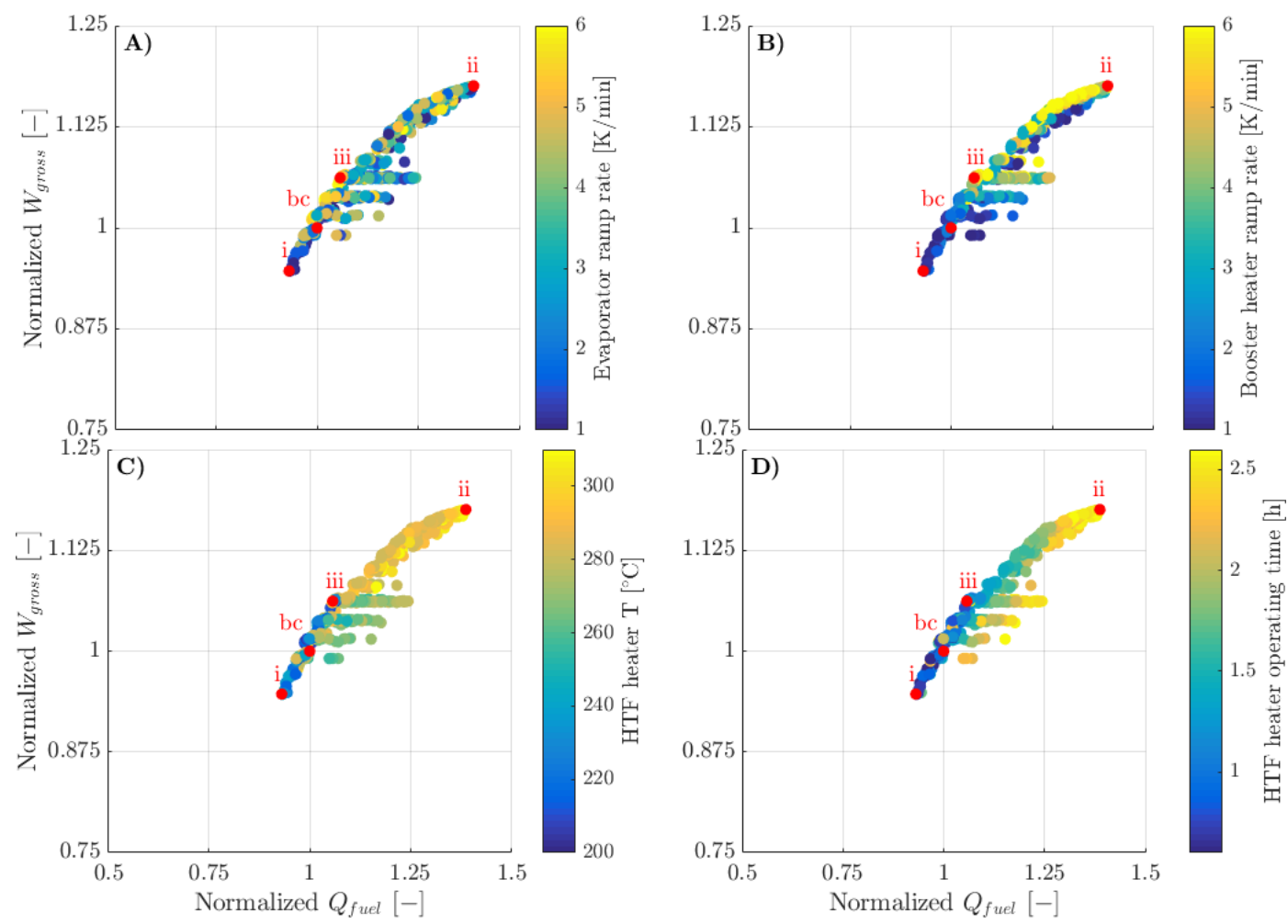

Figure 13: Optimization results for the spring case considering the different decision variables. Values normalized towards the base case results. A) Evaporator start-up rate constraints. B) Booster heater start-up rate. C) HTF heat Temperature D) HTF heater operating time.

\section{Conclusions}

A detailed model was used to find the optimal start-up operational strategy of a gas-boosted parabolic trough power plant. The model was developed in DYESOPT - a techno-economic tool for dynamic performance evaluation of power plants. The power block part of the model was developed accounting for the heating rate constraints of the steam generator system, booster heater and the steam turbine startup control strategy. The model was validated both at steady-state and dynamic operating conditions, and subsequently used to optimize the start-up strategy by minimizing the fuel consumption and maximizing the electric energy production by means of a genetic algorithm based multi-objective optimizer. Both the validation and optimization were performed for two different time series corresponding to a winter and a spring case, respectively.

The results of the validation indicate that the model is able to predict with a reasonable accuracy the behavior of a gas-boosted parabolic trough solar power plant, both at steady state and dynamic operating 
conditions. The validation at steady-state condition shows a maximum relative error of $-6.7 \%$ for the SGS HTF mass flow rate and $-5.1 \%$ for the total electric parasitic consumption. For dynamic operating conditions, the validation results in a maximum NRMSE of $+13.5 \%$ for the solar field HTF mass flow rate, $11.8 \%$ on gross power rise time and a maximum integral relative error of $+4.3 \%$ for gross electric energy production in the case of the spring case. Considering the daily electric energy production, the validation indicates that $85 \%$ of the values are within a $\pm 10 \%$ confidence range.

The result of the multi-objective optimization indicates that it is not possible to define a range of optimal heating rates for evaporator constraints. However, different optimal start-up strategies can be identified. If minimum fuel consumption is desirable, the heating rates would result optimal around the lower threshold of $1 \mathrm{~K} / \mathrm{min}$ together with low utilization of the heat transfer fluid heater. An opposite conclusion can be drawn if maximum electric production is desirable, resulting in a higher utilization of the heat transfer fluid heater both in terms of higher set point temperature and in time of activation. If however the operating strategy is to maximize the plant performance with regards to the electricity production to fuel consumption ratio, higher evaporator heating rates are desirable, namely, $5.7 \mathrm{~K} / \mathrm{min}$ and $6 \mathrm{~K} / \mathrm{min}$ for the winter and spring cases, respectively. These values are representative for steam generators that are commercially available. As a general conclusion, it can be stated that even though an optimal value for the operation of the power plant can be lower than the maximum constraints stated by the manufacturer, it may be desirable to design the evaporator for higher constraints, enabling more flexibility regarding operating strategies. It is therefore clear that it is critical to take into consideration the heating rates constraints when finding the optimal start-up strategies of CSP plants.

\section{References}

Aalborg CSP, 2015. Aalborg CSP Steam Generator [WWW Document]. URL http://www.aalborgcsp.com/quickmenu/brochures/ (accessed 8.3.17).

Al-Hanaei, S., Al-Shomali, S., Abutayeh, M., 2016. Performance Model of Shams I Solar Power Plant. Heat Transf. Eng. 37, 1445-1454. https://doi.org/10.1080/01457632.2016.1142312

Almasabi, A., Alobaidli, A., Zhang, T.J., 2015. Transient characterization of multiple parabolic trough 
Alobaidli, A., Sanz, B., Behnke, K., Witt, T., Viereck, D., Schwarz, M.A., 2017. Shams 1 - Design and operational experiences of the $100 \mathrm{MW}-540^{\circ} \mathrm{C} \mathrm{CSP}$ plant in Abu Dhabi, in: AIP Conference Proceedings. pp. 1-10. https://doi.org/10.1063/1.4984325

ASHRAE, 2000. Ashrae handbook HVAC Systems and Equipment, I-P Editio. ed. Tullie Circle, N.E., Atlanta, GA.

Basaran, I., 2015. A Comprehensive Study of the Imposed Limitations on Concentrating Solar Power Plant Start-up Speeds. MSc, Thesis. Royal Institute of Technology (KTH), Stockholm.

Bergman, T., Lavine, A., Incropera, F., Dewitt, D., 2011. Fundamentals of heat and mass transfer, 7th ed. John Wiley and sons.

Biencinto, M., González, L., Valenzuela, L., 2016. A quasi-dynamic simulation model for direct steam generation in parabolic troughs using TRNSYS. Appl. Energy 161, 133-142. https://doi.org/10.1016/j.apenergy.2015.10.001

Biencinto, M., González, L., Zarza, E., Díez, L.E., Muñoz-antón, J., 2014. Performance model and annual yield comparison of parabolic-trough solar thermal power plants with either nitrogen or synthetic oil as heat transfer fluid. Energy Convers. Manag. 87, 238-249. https://doi.org/10.1016/j.enconman.2014.07.017

Blair, N., Mehos, M., Christensen, C., Cameron, C., 2008. Modeling Photovoltaic and Concentrating Solar Power Trough Performance, Cost, and Financing with the Solar Advisor Model, in: SOLAR 2008 - American Solar Energy Society (ASES). pp. 1-7.

Blanco, D., Luis, A., Garc1, I.L., 2011. Performance model for parabolic trough solar thermal power plants with thermal storage : Comparison to operating plant data. Sol. Energy 85, 2443-2460. https://doi.org/10.1016/j.solener.2011.07.002 
Bonilla, J., Jose, L., 2012. Parabolic-trough solar thermal power plant simulation scheme , multi-objective genetic algorithm calibration and validation. Sol. Energy 86, 531-540. https://doi.org/10.1016/j.solener.2011.10.025

Boukelia, T.E., Arslan, O., Mecibah, M.S., 2017. Potential assessment of a parabolic trough solar thermal power plant considering hourly analysis : ANN-based approach. Renew. Energy 105, 324-333. https://doi.org/10.1016/j.renene.2016.12.081

Boukelia, T.E., Mecibah, M.S., Kumar, B.N., Reddy, K.S., 2015. Investigation of solar parabolic trough power plants with and without integrated TES ( thermal energy storage ) and FBS ( fuel backup system ) using thermic oil and solar salt. Energy 88, 292-303. https://doi.org/10.1016/j.energy.2015.05.038

CEN, 2012. Water-tube boilers and auxiliary installations - Part 3: Design and calculation for pressure parts of the boiler. Brussels.

Dersch, J., Schwarzbözl, P., Richert, T., 2011. Annual Yield Analysis of Solar Tower Power Plants With GREENIUS. J. Sol. Energy Eng. 133, 031017. https://doi.org/10.1115/1.4004355

DLR, 2006. A TRNSYS Model Library for Solar Thermal Electric Components ( STEC ), Reference manual.

Dudley, V., 1994. SEGS LS-2 Solar Collector. Test Results. Sandia National Laboratories. Albuquerque, New Mexico.

Dzierwa, P., Taler, D., Trojan, M., Taler, J., 2016. Evaporator Heating with Optimum Fluid Temperature Changes. Procedia Eng. 157, 29-37. https://doi.org/10.1016/j.proeng.2016.08.334

Dzierwa, P., Taler, J., 2014. Optimum Heating of Pressure Vessels With Holes. J. Press. Vessel Technol. 137, 011202. https://doi.org/10.1115/1.4027584

Estela, Greenpeace, Solarpaces, 2016. Solar Thermal Electricity - Global Outlook 2016. 
Ferruzza, D., Topel, M., Basaran, I., Laumert, B., Haglind, F., 2017. Start-Up Performance of Parabolic Trough Concentrating Solar Power Plants, in: AIP Conference Proceedings 1850. pp. 1-9. https://doi.org/10.1063/1.4984542

Ferruzza, D., Topel, M., Laumert, B., Haglind, F., 2018. Impact of steam generator start-up limitations on the performance of a parabolic trough solar power plant. Sol. Energy 169. https://doi.org/10.1016/j.solener.2018.05.010

Gilman, P., Laboratory, N.R.E., Laboratories, S.N., 2008. Solar advisor model user guide for version 2.0. Technical Report.

González-Gómez, P.A., Petrakopoulou, F., Briongos, J.V., Santana, D., 2017. Cost-based design optimization of the heat exchangers in a parabolic trough power plant. Energy 123, 314-325. https://doi.org/10.1016/j.energy.2017.02.002

González-Gómez, P.Á., Petrakopoulou, F., Briongos, J.V., Santana, D., 2017. Steam generator design for solar towers using solar salt as heat transfer fluid, in: AIP Conference Proceedings. pp. 1-8. https://doi.org/10.1063/1.4984363

Groupe Reaction Inc., 2014. CSP Parabolic Trough Report : Cost, Performance and Key Trends. London.

Guédez, R., 2016. A Techno-Economic Framework for the Analysis of Concentrating Solar Power Plants with Storage. Ph.D. Thesis. Royal Institute of Technology, (KTH), Stockholm.

International Energy Agency, 2014. Technology Roadmap, Solar Thermal Electricity. Paris.

Khetarpal, D., 2016. World Energy Resources: Solar 2016, World Energy Council.

Leyland, G.B., Favrat, D., 2002. Multi-objective optimization applied to industrial energy problems. Ph.D. Thesis. Mech. Eng. École Polytechnique Féderale de Lausanne, (EPFL), Lausanne. https://doi.org/doi:10.5075/epfl-thesis-2572

Li, L., Li, Y., Sun, J., 2017a. Prospective fully-coupled multi-level analytical methodology for 
Li, L., Sun, J., Li, Y., 2017b. Prospective fully-coupled multi-level analytical methodology for concentrated solar power plants: General modelling. Appl. Therm. Eng. 118, 171-187. https://doi.org/10.1016/j.applthermaleng.2017.02.086

Li, L., Sun, J., Li, Y., 2017c. Thermal load and bending analysis of heat collection element of directsteam-generation parabolic-trough solar power plant. Appl. Therm. Eng. 127, 1530-1542. https://doi.org/10.1016/j.applthermaleng.2017.08.129

Lippke, F., 1995. Simulation of the Part-Load Behavior of a 30 Mwe SEGS Plant. Report. Sandia National Laboratories. Albuquerque, New Mexico.

Mancini, T.R., Gary, J.A., Kolb, G.J., Ho, C.K., 2011. Power Tower Technology Roadmap and cost reduction plan. Sandia Report. Sandia National Laboratories. Albuquerque, New Mexico. https://doi.org/10.2172/1011644

Moya, E.Z., 2012. Parabolic-trough concentrating solar power (CSP) systems, in: Concentrating Solar Power Technology. Woodhead publishing, Cambridge, UK, pp. 197-239. https://doi.org/10.1533/9780857096173.2.197

Price, H., 2003. A Parabolic Trough Solar Power Plant Simulation Model, in: ASME. International Solar Energy Conference. pp. 665-673. https://doi.org/doi:10.1115/ISEC2003-44241

Schenk, H., Dersch, J., Hirsch, T., Polklas, T., 2015. Transient Simulation of the Power Block in a Parabolic Trough Power Plant. Proc. 11 Int. Model. Conf. 605-614. https://doi.org/10.3384/ecp15118605

Solutia, 2014. Therminol VP-1, Solutia.

Spelling, J., 2013. Hybrid Solar Gas-Turbine Power Plants - A Thermoeconomic Analysis. PhD Thesis. Royal Institute of Technology, (KTH), Stockholm. 
Spelling, J., Jöcker, M., Martin, A., 2012. Annual performance improvement for solar steam turbines through the use of temperature-maintaining modifications. Sol. Energy 86, 496-504. https://doi.org/10.1016/j.solener.2011.10.023

STEAG, 2012. Ebsilon professional [WWW Document]. URL https://www.steagsystemtechnologies.com/sst-home.html (accessed 12.1.17).

Stoddard, M.C., Faas, S.E., Chiang, C.J., Dirks, J. a, 1987. SOLERGY - A Computer Code for Calculating the Annual Energy from Central Receiver Power Plants. Sandia Report. Sandia National Laboratories. Albuquerque, New Mexico.

Sun, J., Liu, Q., Hong, H., 2015. Numerical study of parabolic-trough direct steam generation loop in recirculation mode : Characteristics , performance and general operation strategy. Energy Convers. Manag. 96, 287-302. https://doi.org/10.1016/j.enconman.2015.02.080

Taler, J., Dzierwa, P., Taler, D., Harchut, P., 2015a. Optimization of the boiler start-up taking into account thermal stresses. Energy 92, 160-170. https://doi.org/10.1016/j.energy.2015.03.095

Taler, J., Weglowski, B., Taler, D., Sobota, T., Dzierwa, P., Trojan, M., Madejski, P., Pilarczyk, M., 2015b. Determination of start-up curves for a boiler with natural circulation based on the analysis of stress distribution in critical pressure components. Energy 92, 153-159. https://doi.org/10.1016/j.energy.2015.03.086

Topel, M., Guédez, R., Laumert, B., 2015. Impact of Increasing Steam Turbine Flexibility on the Annual Performance of a Direct Steam Generation Tower Power Plant. Energy Procedia 69, 1171-1180. https://doi.org/10.1016/j.egypro.2015.03.196

Topel, M., Jöcker, M., Paul, S., Laumert, B., 2015. Differential Expansion Sensitivity Studies During Steam Turbine Startup. J. Eng. Gas Turbines Power 138, 062102. https://doi.org/10.1115/1.4031643

Topel, M., Nilsson, Å., Jöcker, M., Laumert, B., 2017. Investigation Into the Thermal Limitations of 

https://doi.org/10.1115/1.4037664

University of Wisconsin Madison. Solar Energy Laboratory., 1975. TRNSYS, a transient simulation 643 program. Madison, Wis. : The Laboratory, 1975.

Vogel, T., Oeljeklaus, G., Görner, K., Dersch, J., Polklas, T., 2014. Hybridization of parabolic trough power plants with natural gas. Energy Procedia 49, 1238-1247.

646 https://doi.org/10.1016/j.egypro.2014.03.133

647

648 